\title{
Technological forecasting related to the energy sector: a scientometric overview
}

\author{
Alexey V. Mikheev ${ }^{1, *}$ \\ ${ }^{1}$ Melentiev Energy Systems Institute of Siberian Branch of the Russian Academy of Sciences, 130, Lermontov str., \\ 664033, Irkutsk, Russia
}

\begin{abstract}
Scientometric review of trends and key points of technological forecasting related to the energy sector is carried out in this study. Using co-keyword, co-citation techniques to analyze a set of research and review articles indexed in the Scopus database, clustered networks were built to understand content relationships and research topic evolution within the 2000-2019 period. This study provides an overview of future-oriented research efforts and trends in the energy technology knowledge domain.
\end{abstract}

Keywords: energy technology, technological forecasting, scientometric analysis, visual analytic, VOSviewer, CiteSpace.

\section{Introduction}

Technology forecasting is usually determined as decisive and systematic attempts to anticipate and understand the potential direction, rate, characteristics, and effects of technological changes, especially invention, innovation, adoption, and use [1]. In [2] the group of experts systematizes methods and forms of technology forecasting within a future-oriented technology analysis framework. They distinguish several overlapping forms of technology forecasting such as:

- technology monitoring, watch, alerts (gathering and interpreting information);

- competitive intelligence (converting that information into usable intelligence);

- technology forecasting (anticipating the direction and pace of changes);

- technology roadmapping (relating anticipated advances in technologies and products to generate plans);

- technology assessment (anticipating the unintended, indirect, and delayed effects of technological changes);

- technology foresight (effecting development strategy, often involving participatory mechanisms).

In recent decades, the works [3] and [4] review the families of technology forecasting methods, its relationships, and applications. Nevertheless, there are no general overviews of technology forecasting evolution applied to the energy sector. This research tries to investigate the impact of energy technology forecasting in the scientific literature.
The energy technology forecasting concept is not always used to imagine prospects and the coming advances in the energy area. Many works anticipating future energy technologies use "technological change" or widely discussed "energy transition" toward sustainable development by transitioning from fossil-based to zerocarbon energy resources [5]. So these concepts should be additionally involved in the consideration.

The main goals of this study:

- summarizing the recent existing research efforts on energy technology forecasting;

- helping to systematically understand the cocitation documents, term clusters, and keywords clusters, as well as the knowledge pattern of energy technology forecasting;

- quantitative estimation of the status quo and development trend of energy technology forecasting;

- visualization of the research landscape of technology forecasting in the energy area.

\section{Methodology, data, and tools}

The methodology of the study is a scientometric analysis joint with supporting visualization to provide an in-depth understanding of the research structure and trending topics in energy technology forecasting. The scientometric analysis is a well-established technique to construct a knowledge map of the specific area over a large massive dataset of scientific literature. An example of a scientometric review of global research on

\footnotetext{
Corresponding author: avmiheev@gmail.com
} 
sustainability and sustainable development can be found in [6]. General workflow of scientometric analysis includes several sequential steps:

1. Publications data retrieval related to a specific problem or knowledge area.

2. Data cleaning manually or automatically to remove irrelevant publications.

3. Scientometric quantitative analysis applying various metrics like betweenness centrality, burst strengths to construct different co-occurrence networks. The network examples are co-authorship network, coword network, co-terms network, co-citations network, and others. Further cluster analysis over the constructed networks is also a part of the scientometric approach.

4. Knowledge domain visualization and in-depth analysis to obtain status-quo of research, discover emerging trends, hidden interrelations, and other valuable outputs.

In the study, the Scopus database was selected as the most comprehensive and easy-to-use data source. A search in the database was carried out using the base word "energy" and a specific set of additional words related to concepts of future-oriented technology analysis. The last concept has fuzzy semantics and includes such terms as "technology forecasting", "technology foresight", "technology monitoring”, "technology roadmapping", "technology trend", "technology assessment", "technology change", "technology transition" and so on. Symbol "*" is inserted instead of the end of some words to satisfy a fuzzy search. The publications with the language "English" and document type as "Article", "Review" from reviewed and trusted journals were selected. We consider the period 2000-2019 when the rapid growth of publications in the Scopus database is observed.

The final query text inserted in the bar of "Advanced search" of the Scopus search engine is presented below.

TITLE-ABS-KEY ( energy AND ( "technol* forecast*" OR "forecast* technol*" OR "technol* trend*" OR "technol* monitoring" OR "technol* chang*" OR "technol* transit*" OR "technol* transform*" OR "emerging energy technol*" OR "technol*assess*" OR "technol* roadmap*" OR (technolog* AND "future prospect*"))) AND (LIMITTO ( DOCTYPE, "ar") OR LIMIT-TO ( DOCTYPE, "re")) AND (LIMITTO ( LANGUAGE, "English" ) )

To avoid including irrelevant documents, for example from medical science, the search results were filtered to remove the subject areas far from "Energy" like "Medicine", "Nursery", "Computer Science", "Arts and Humanities", etc. On the other hand, since the "energy" is a multidisciplinary topic, such subject categories as "Engineering", "Chemistry", "Environmental Science", "Social Science", "Material Science" and so on also remain under consideration.

The search with this query gives 3448 articles. Fig.
1 presents the document statistics by years, countries, and sources provided by the standard Scopus tool.

To investigate semantic content, key topics, and its corresponding interrelations the two scientometric techniques were used in this study, namely, co-citation analysis and co-term (keyword) analysis.

In this paper, two software tools are used for scientometric analysis. First, VOSviewer software pays special attention to displaying large bibliometric maps in an easy-to-interpret way [7]. Another one is CiteSpace, which is a very powerful and extremely featured application for analyzing and visualizing co-citation scientific networks [8]. The software developed by Chaomei Chen has rich possibilities to identify the emerging trends and general points in a specific domain.

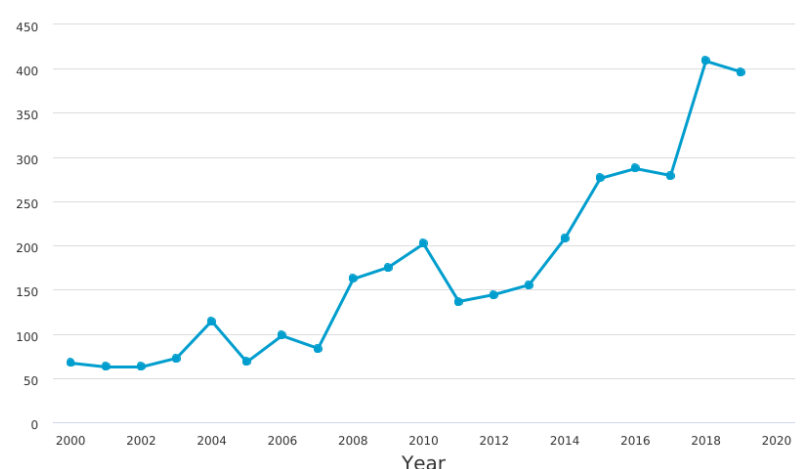

a)

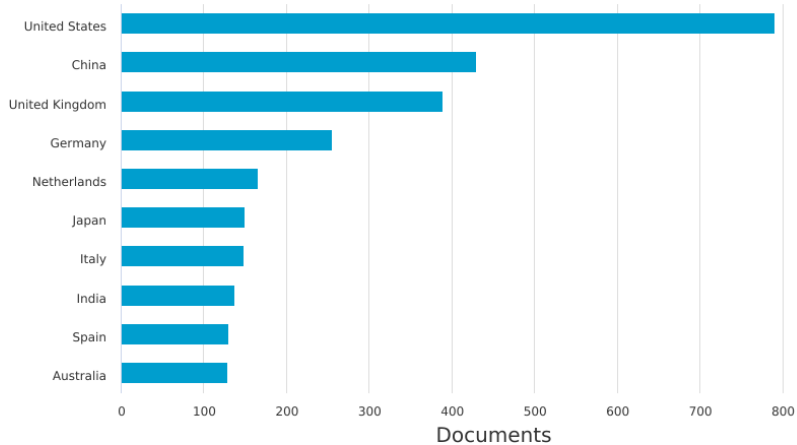

b)

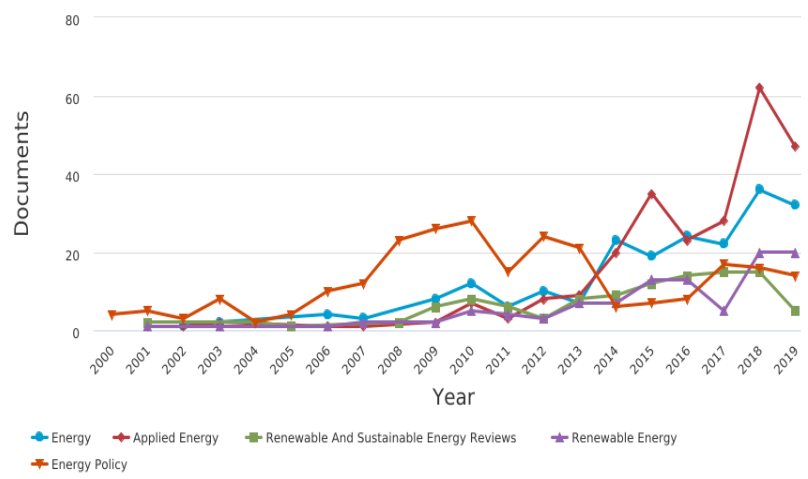

c)

Fig. 1. The number of articles on energy technology forecasting in the Scopus database: (a) during period 2000-2019, (b) country distribution, (c) most productive journals. 


\section{Results of scientometric analysis}

Initially, the co-occurrence network based on the article's keywords was generated with VOSViewer. General terms like "article", "review", "technology" were excluded from the keywords list summarized from all articles. The visualization of the clustered network graph is shown in Fig. 2.

Several colored clusters found over the keywords network reflect the main research topics of two recent decades. Technological change implies the advancement of renewable energy resources such as wind energy and solar energy (mixed violet and blue clusters). The red cluster contains another class of renewable energy technologies based on biomass. The bioenergy cluster is linked to renewable solar and wind technologies through hydrogen technologies including fuel cells. The green cluster presents energy policy issues including planning and market development for renewable energy sources on the one hand. On the other hand, climate change and emission control issues are directly related to environmental protection and carbon dioxide emissions topics located in the yellow cluster. Such general terms as energy efficiency, energy conversion, energy consumption, performance assessment, electric power system development, and other issues remain important research topics.

Generating a co-citation network using CiteSpace software with default parameters is the next step of the analysis. For the correct construction of the co-citation network, the publications of the years preceding 2000 were also included to consider previous research impact. Co-citation network in Fig. 3 presents an evolution of technology forecasting research from 2000 to 2019 years. It's observed that the presented co-citation graph becomes sparser during the last decade 2010-2020.

The list of top 47 papers having the strongest citation burst is shown in Fig. 4. These papers are sorted by start year of burst to show the dynamics of the "hottest" documents and its corresponding topics along with the considered period. The main theme of these papers is a discussion about appropriate technological changes as responses on the global problems of climate change and sustainable development of the world economy. Types of almost all highly cited works are reviews, surveys or theory foundation books.

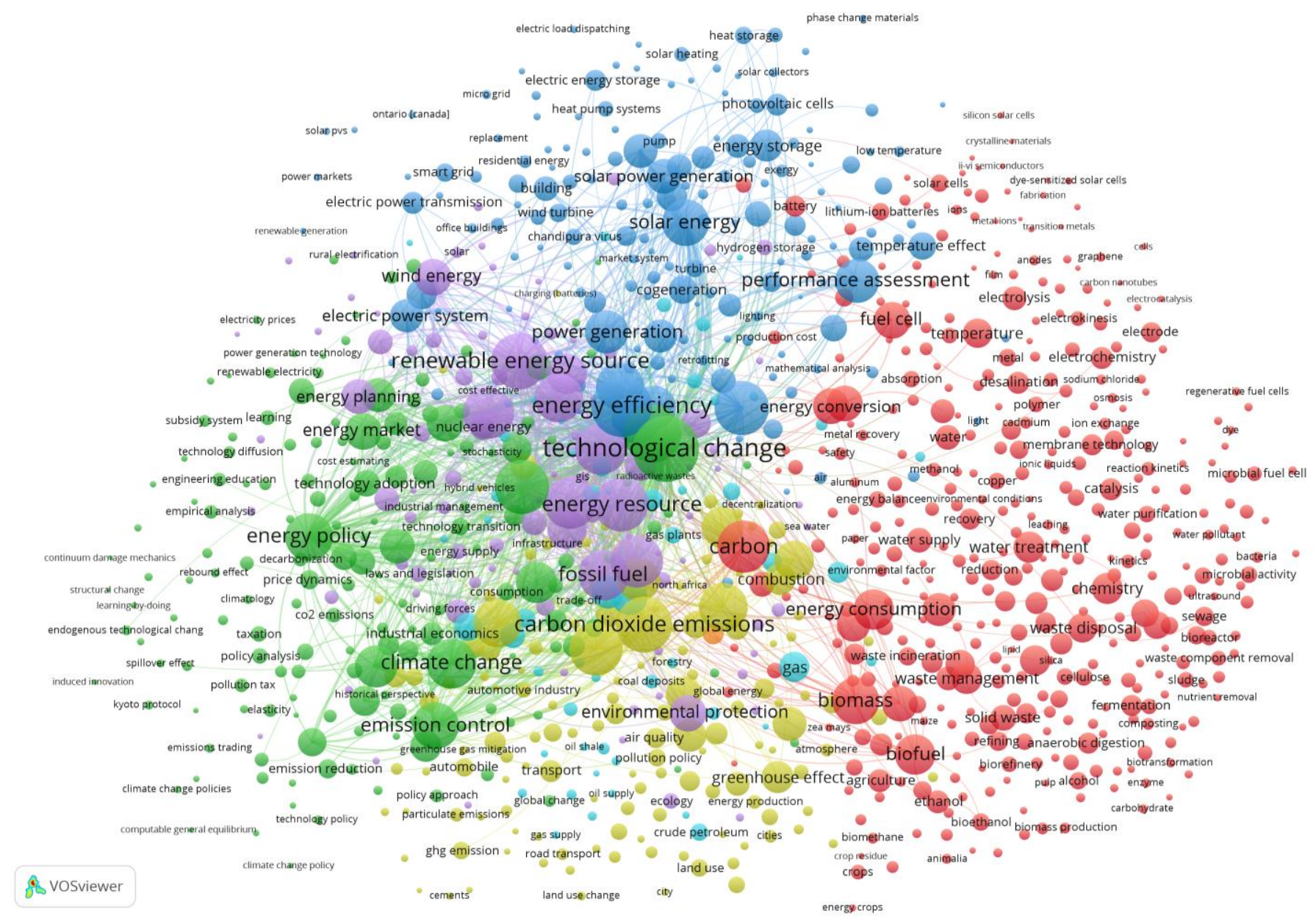

Fig. 2. Colored clusters of keywords co-occurrence network generated using VOSviewer software. 


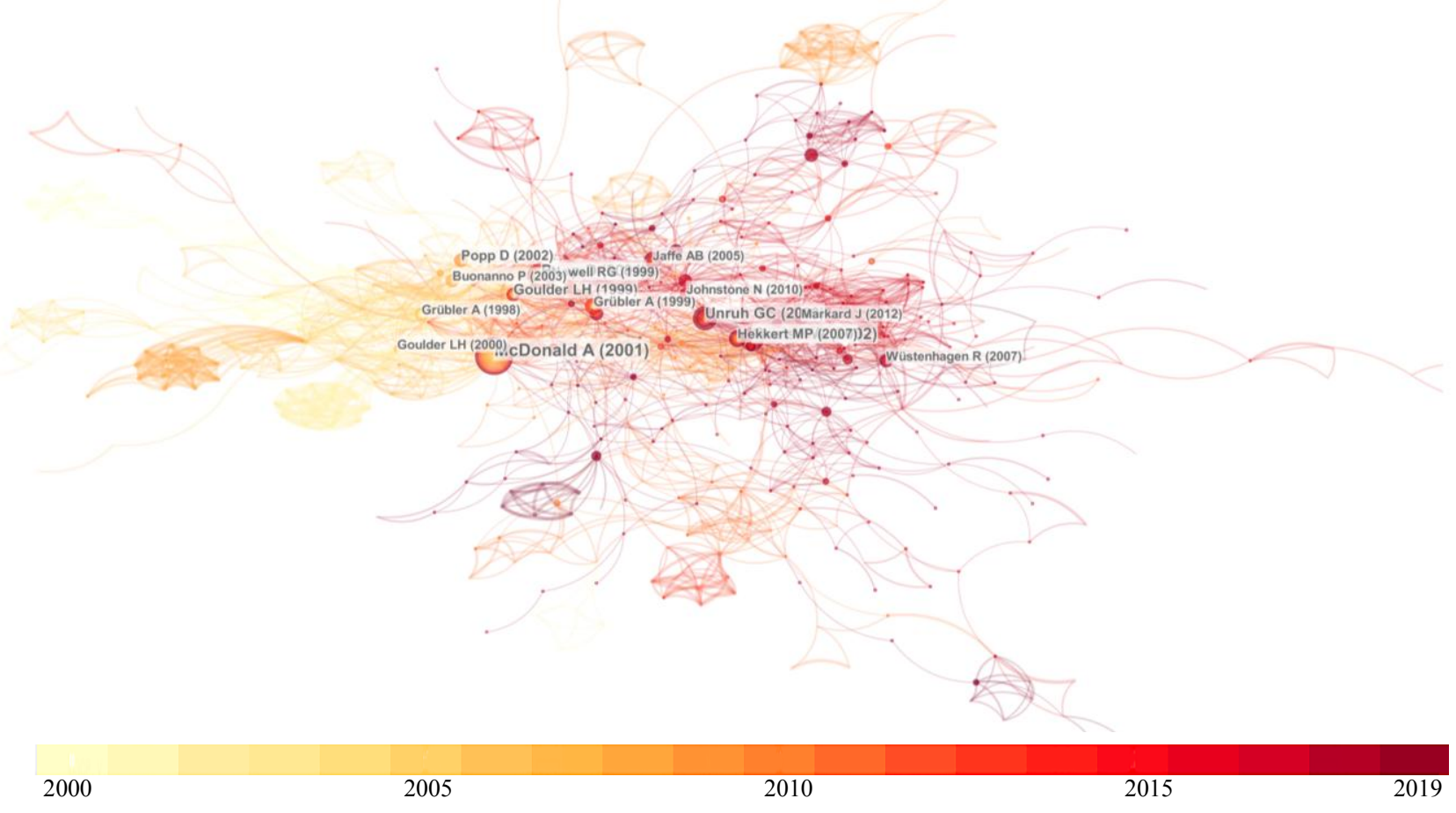

Fig. 3. Co-citation network from publications of Scopus database over period of 2000-2019 years.

References
Messner S, 1997, Endogenised technological learning in an energy systems ..., V7, P291-313 Grübler A, 1998, Technology and Global Change @ , V0, P0

Nakicenovic N, 1998, Global Energy Perspectives @ , V0, P0

McDonald A, 2001, Learning rates for energy technologies @ ENERGY POLICY ..., V29, P255-261 Goulder LH, 2000, Optimal $\mathrm{CO} 2$ abatement in the presence of induced technological ..., V39, P1-38 Goulder LH, 1999, Induced technological change and the attractiveness ..., V21, P211-253

Mattsson N, 1997, Assessing new energy technologies using an energy system ..., V21, P385-393 Newell RG, 1999, The induced innovation hypothesis and energy-saving ..., V114, P941-975 Argote L, 1990, Learning curves in manufacturing @ SCIENCE, V247, P920-924 Grubb M, 2002, Induced technical change in energy and environmental ..., V27, P271-308 Popp D, 2001, The effect of new technology on energy consumption ..., V23, P215-239 Jacobsson S, 2000, The diffusion of renewable energy technology, V28, P625-640 Kemp R, 1998, Regime shifts to sustainability through processes of ..., V10, P175-195 Nordhaus WD, 1994, Managing the Global Commons, V0, P0

Gerlagh R, 2003, Gross world product and consumption in a global warming ..., V25, P35-57 Popp D, 2002, Induced innovation and energy prices @ AMERICAN ECONOMIC ..., V92, P160-180 Popp D, 2004, ENTICE, V48, P742-768

Buonanno P, 2003, Endogenous induced technical change and the costs of ..., V25, P11-34 Acemoglu D, 2002, Directed technical change @ REVIEW OF ECONOMIC STUDIES ..., V69, P781-809 Rip A, 1998, Technological change @ HUMAN CHOICE AND CLIMATE CHANGE ..., V2, P0 Stern N, 2007, The Economics of Climate Change, V0, PO

Markard J, 2008, Technological innovation systems and the multi-level ..., V37, P596-615 De Piante Henriksen A, 1997, A technology assessment primer for management of technology ..., V13, P615-638 Färe R, 1994, Productivity growth, technical progress, and ..., V84, P66-83

Kern F, 2008, Restructuring energy systems for sustainability?, V36, P4093-4103

Grübler A, 1999, Dynamics of energy technologies and global change @ ..., V27, P247-280 Ferioli F, 2009, Use and limitations of learning curves for energy technology ..., V37, P2525-2535 Nemet GF, 2006, Beyond the learning curve, V34, P3218-3232

Johnstone N, 2010, Renewable energy policies and technological innovation ..., V45, P133-155 Chung YH, 1997, Productivity and undesirable outputs, V51, P229-240

Fischer C, 2008, Environmental and technology policies for climate mitigation ..., V55, P142-162 Wüstenhagen $R, 2007$, Social acceptance of renewable energy innovation, V35, P2683-2691 Markard J, 2012, Sustainability transitions, V41, P955-967

Acemoglu D, 2012, The environment and directed technical change @ AM ..., V102, P131-166 Kriegler E, 2014, The role of technology for achieving climate policy ..., V123, P353-367 Geels FW, 2011, The multi-level perspective on sustainability transitions ..., V1, P24-40 Jacobson MZ, 2011, Providing all global energy with wind, water, ..., V39, P1154-1169 Jacobsson S, 2006, The politics and policy of energy system transformation ..., V34, P256-276 Peters M, 2012, The impact of technology-push and demand-pull policies ..., V41, P1296-1308 $\mathrm{Su}$ B, 2012, Structural decomposition analysis applied to energy ..., V34, P177-188 Turnheim B, 2013, The destabilisation of existing regimes, V42, P1749-1767 Chu S, 2012, Opportunities and challenges for a sustainable energy ..., V488, P294-303 Kivimaa P, 2016, Creative destruction or mere niche support?, V45, P205-217 Luo X, 2015, Overview of current development in electrical energy ..., V137, P511-536 Ang BW, 2004, Decomposition analysis for policymaking in energy, V32, P1131-1139 Nykvist B, 2015, Rapidly falling costs of battery packs for electric ..., V5, P329-332 Rubin ES, 2015, A review of learning rates for electricity supply technologies ..., V86, P198-218

\begin{tabular}{lrl} 
Year Strength Begin End \\
1997 & $5.1843 \mathbf{2 0 0 0}$ & 2004 \\
1998 & $7.6396 \mathbf{2 0 0 0}$ & 2007 \\
1998 & $3.4511 \mathbf{2 0 0 0}$ & 2004 \\
2001 & $8.5072 \mathbf{2 0 0 2}$ & 2012 \\
2000 & $5.5228 \mathbf{2 0 0 2}$ & 2008 \\
1999 & $4.1715 \mathbf{2 0 0 3}$ & 2009 \\
1997 & $3.1934 \mathbf{2 0 0 3}$ & 2004 \\
1999 & $3.6389 \mathbf{2 0 0 4}$ & 2008 \\
1990 & $4.4955 \mathbf{2 0 0 4}$ & 2007 \\
2002 & $3.5716 \mathbf{2 0 0 4}$ & 2008 \\
2001 & $3.5856 \mathbf{2 0 0 4}$ & 2006 \\
2000 & $3.9312 \mathbf{2 0 0 5}$ & 2010 \\
1998 & $3.9312 \mathbf{2 0 0 5}$ & 2010 \\
1994 & $3.1554 \mathbf{2 0 0 5}$ & 2006 \\
2003 & $5.1502 \mathbf{2 0 0 5}$ & 2008 \\
2002 & $8.3398 \mathbf{2 0 0 5}$ & 2010 \\
2004 & $7.6643 \mathbf{2 0 0 5}$ & 2009 \\
2003 & $8.7436 \mathbf{2 0 0 5}$ & 2008 \\
2002 & $3.1912 \mathbf{2 0 0 6}$ & 2010 \\
1998 & $4.0037 \mathbf{2 0 0 7}$ & 2010 \\
2007 & $3.4291 \mathbf{2 0 0 8}$ & 2011 \\
2008 & $3.5256 \mathbf{2 0 0 9}$ & 2010 \\
\hline 1997 & $3.5939 \mathbf{2 0 1 1}$ & 2012 \\
1994 & $4.0341 \mathbf{2 0 1 1}$ & 2014 \\
2008 & $3.302 \mathbf{2 0 1 2}$ & 2014 \\
1999 & $3.6705 \mathbf{2 0 1 2}$ & 2014 \\
\hline 2009 & $3.2291 \mathbf{2 0 1 2}$ & 2013 \\
2006 & $3.4727 \mathbf{2 0 1 2}$ & 2018 \\
2010 & $6.3747 \mathbf{2 0 1 3}$ & 2017 \\
1997 & $5.1062 \mathbf{2 0 1 3}$ & 2016 \\
2008 & $4.8062 \mathbf{2 0 1 4}$ & 2018 \\
2007 & $3.7744 \mathbf{2 0 1 4}$ & 2020 \\
2012 & $5.0054 \mathbf{2 0 1 4}$ & 2017 \\
2012 & $3.2681 \mathbf{2 0 1 4}$ & 2020 \\
2014 & $3.4436 \mathbf{2 0 1 5}$ & 2017 \\
2011 & $3.9079 \mathbf{2 0 1 6}$ & 2020 \\
2011 & $3.8205 \mathbf{2 0 1 6}$ & 2017 \\
2006 & $5.3655 \mathbf{2 0 1 6}$ & 2018 \\
2012 & $3.2731 \mathbf{2 0 1 6}$ & 2017 \\
2012 & $4.0555 \mathbf{2 0 1 7}$ & 2020 \\
2013 & $3.1737 \mathbf{2 0 1 7}$ & 2018 \\
2012 & $3.7045 \mathbf{2 0 1 7}$ & 2018 \\
2016 & $3.1737 \mathbf{2 0 1 7}$ & 2018 \\
2015 & $4.3839 \mathbf{2 0 1 7}$ & 2020 \\
2004 & $3.7045 \mathbf{2 0 1 7}$ & 2018 \\
2015 & $6.081 \mathbf{2 0 1 8}$ & 2020 \\
2015 & $5.5589 \mathbf{2 0 1 8}$ & 2020 \\
\hline
\end{tabular}

Fig. 4. Top 47 papers with strongest citation bursts. Most intensive citation period is selected by red color. 
There are several key topics identified from top-cited papers. First, the learning rates of energy technologies to assess forthcoming technological changes were the most important subject of interest for researchers. A highly cited research study [9] by Alan McDonald and Leo Schrattenholzer considers assembled data on cost reductions for many energy technologies to estimate learning rates. The work [10] by G.F. Nemet discusses the factors influencing cost reductions in photovoltaics. A comprehensive review of learning rates for electricity supply technologies [11] is highly cited in past 3 years. Understanding of nature of learning rates remains a key hot topic during all period $2000-2019$.

The directed technological change related to is another topic widely discussed (see for example [12]). The challenge of restructuring energy systems to provide sustainable technological transition with large-scale involvement of renewable energy sources receives special attention as an important issue of energy policy [13].

\section{Conclusions}

A preliminary scientometric overview was carried out for the research domain of energy technological forecasting. General trends of technology forecasting in the energy sector were quantitatively estimated and visualized. The findings show the research spectrum from environmental policy issues like climate change and emission control to a set of alternative energy technologies including renewable solar, wind, biomass, and hydrogen technologies. However, to discover non-evident topics and relationships the deeper analysis is needed together with further comprehensive critical review similar to the methodology used in [14]. This analysis can also be improved on the base of the iterative procedure using preliminary prepared hierarchical concept maps or applied ontologies of energy technologies and forecasting methods.

\section{Acknowledgments}

The research is funded by the Russian Foundation for Basic Research (project No. 20-07-00994).

\section{References}

1. V. Coates, M. Faroque, R. Klavins et al. On the future of technological forecasting. Technol. Forecast. Soc. Change, 67 (1), 2001. pp. $1-17$. https://doi.org/10.1016/S0040-1625(00)00122-0

2. Technology Futures Analysis Methods Working Group, Technology Futures Analysis: Toward Integration of the Field and New Methods, Technological Forecasting and Social Change, Vol. 71, 2004. pp. 287-303.

3. Firat, A.K., Woon, W.L., Madnick, S. Technological Forecasting - A Review, Working Paper, Massachusetts Institute of Technology, Report, USA, 2008.

4. Haleem, A., Mannan, B., Luthra, S., Kumar, S. and Khurana, S. Technology forecasting (TF) and technology assessment (TA) methodologies: a conceptual review, Benchmarking: An International Journal, Vol. 26 No. 1, 2019, pp. 48-72. https://doi.org/10.1108/BIJ-04-2018-0090

5. Grübler, A., Nakićenović, N., \& Victor, D. G. Dynamics of energy technologies and global change. Energy Policy, 27(5), 1999. pp. 247-280. https://doi.org/10.1016/S0301-4215(98)00067-6

6. Olawumi, T. O., \& Chan, D. W. M. A scientometric review of global research on sustainability and sustainable development. Journal of Cleaner Production, 183, 2018. Pp. 231-250. https://doi.org/10.1016/J.JCLEPRO.2018.02.162

7. Van Eck, N. J., \& Waltman, L. Software survey: VOSviewer, a computer program for bibliometric mapping. Scientometrics, 84(2), 2010. 523-538. https://doi.org/10.1007/s11192-009-0146-3

8. Chen, C., Song, M. Visualizing a field of research: A methodology of systematic scientometric reviews. PLoS ONE, 14(10), 2019. https://doi.org/10.1371/journal.pone.0223994

9. McDonald, A., \& Schrattenholzer, L. Learning rates for energy technologies. Energy Policy, 29(4), 2001. pp. 255-261. https://doi.org/10.1016/S0301$\underline{4215(00) 00122-1}$

10. Nemet, G. F. (2006). Beyond the learning curve: factors influencing cost reductions in photovoltaics. Energy Policy, 34(17), 3218-3232. https://doi.org/10.1016/j.enpol.2005.06.020

11. Rubin, E. S., Azevedo, I. M. L., Jaramillo, P., \& Yeh, S. (2015). A review of learning rates for electricity supply technologies. Energy Policy, 86, 198-218. https://doi.org/10.1016/j.enpol.2015.06.011

12. Acemoglu, D., Aghion, P., Bursztyn, L., Hemous, D. (2012). The Environment and Directed Technical Change. American Economic Review, 102(1), 131166.

13. Wüstenhagen, R., Wolsink, M., \& Bürer, M. J. (2007). Social acceptance of renewable energy innovation: An introduction to the concept. Energy Policy, 35(5), 2683-2691. https://doi.org/10.1016/j.enpol.2006.12.001

14. Zhong, B., Wu, H., Li, H., Sepasgozar, S., Luo, H., \& He, L. (2019). A scientometric analysis and critical review of construction related ontology research. Automation in Construction, 101, 2019. pp. 17-31. https://doi.org/10.1016/J.AUTCON.2018.12.013 